DOI: 10.20472/IAC.2018.935.052

\author{
SYLVIA VILLARREAL \\ UNIVERSIDAD INDUSTRIAL DE SANTANDER, Colombia \\ EDNA BRAVO \\ Universidad Industrial de Santander, Colombia
}

\title{
KNOWLEDGE MANAGEMENT IN COLOMBIAN PUBLIC SECTOR - A LITERATURE REVIEW
}

\begin{abstract}
:
One of the main challenges that governments face is managing scarce resources to attend society's needs. To achieve this, among other actions, they have developed initiatives that allow the coordination of technologies, people, processes and structures; however, these actions have had a short-term vision and low impact rates.

To determine the current situation of knowledge management in the Colombian public sector, a literature review was carried out to identify barriers of initiatives from the international context, detect Colombian initiatives and characterize the scientific documentation of the country related with knowledge management.
\end{abstract}

As a result, in Colombia and other emerging economies, knowledge management actions are rarely documented and developed from the scientific and research literature, evidencing the absence of guidelines and guidance tools to create and manage knowledge management initiatives. This delay is attributed to the fact that, in the private sector, it is not considered a strategic issue, and, the academic focus on conceptual approach, research the importance of formulating strategies and the needs of finding an adequate model.

It is emphasized that the implemented approach is related to the use of information technologies, leaving aside the importance of human interaction to create, transfer and appropriate knowledge. The identified Colombian initiatives are from the MinTIC and non-financial public companies, which have focused on the implementation of knowledge management tools and practices and the creation of specialized equipment.

In conclusion, from the international perspective, where innovation is sought to be implemented as a response mechanism to the demands of current citizens, in Colombia there are significant delays in the development and documentation of knowledge management initiatives. Also, although there is a growing interest in the implementation of KM models in the public sector, but they can't achieve be materialized because there are no guidelines or processes for the creation of models that facilitate the transfer of knowledge.

\section{Keywords:}

Colombia, knowledge management, literature review, public sector.

JEL Classification: 031, O32 